\title{
Benign Gingival Neoplasm
}

National Cancer Institute

\section{Source}

National Cancer Institute. Benign Gingival Neoplasm. NCI Thesaurus. Code C4598.

A non-metastasizing neoplasm that arises from the upper or lower gingiva. 